\title{
Synthesis scheelite concentrate electroslag remelting for receiving tungsten steel
}

\author{
Evgeny Kuzmichev ${ }^{1}$ and Sergey Nikolenko ${ }^{2 *}$ \\ ${ }^{1}$ Far Eastern State Transport University, Khabarovsk, Russia \\ ${ }^{2}$ Institute of Materials Science, Khabarovsk Scientific Center, Far Eastern Branch, Russian Academy \\ of Sciences, Khabarovsk, Russia.
}

\begin{abstract}
This article investigates the influence of various reducers of tungsten from a scheelite concentrate on a complex alloying of melted lowcarbonaceous steel by tungsten through an oxides slag system. By electroslag remelting of low-carbon steel using ceramic fluxes on the basis of mineral associations are received high-alloyed by tungsten (to $20 \mathrm{wt} \%$ ).
\end{abstract}

\section{Introduction}

Tungsten in steel forms carbides, reduces the tendency of grain growth when heated to high temperatures and increases overmelting, durability and viscosity. In this regard, tungsten is used to receive tool steel and as alloyed steel, which is used for the details operated at high speeds, shock loadings and vibrations.

However, the high cost of tungsten, the limitation of stocks in crust and the technological and organizational difficulties of receiving tungsten steel in the conditions of sustainable development have resulted in a search for new approaches in order to solve these problems.

An effective solution to this problem is the direct processing of raw mineral materials with receiving composite materials, according to the main conclusions of a mineralogical materialogy $[1,2]$, consisting of reducing the periods between a cycle of receiving raw materials, its processing and a cycle of receiving materials, as well as reducing the periods in each cycle at the expense of using high-level technologies-that is, receiving materials in the region of producing raw materials. We propose using the concentrated streams of energy for receiving materials, including electroslag remelting.

The Far East of the Russian Federation has considerable stocks of tungsten raw materials. In this regard, there was a hypothesis of the possibility of receiving tungsten alloy steel when using electroslag remelting at the application of the fluxes containing a scheelite concentrate in the region of its production. Preliminary research [3, 4] demonstrated such an approach to the problem of receiving tungsten steel. The problem of the complex and rational use of expensive raw mineral materials needs to be solved. In addition, the problem of using these raw materials is connected with the need to reduce the period from the production of raw materials to a cycle of receiving materials and products. The tungsten raw materials go to the western regions of the country and abroad, which

* Corresponding author: nikola1960@mail.ru 
considerably increases the entropy of the environment $[5,6]$. In this regard, the hypothesis is that in tungsten restoration from a scheelite concentrate the electroslag remelting, the essential role is played by the structure of a reducer, which provides the greatest transition of $\mathrm{W}$ in melted steel.

Practical use of this assumption requires research and development of the fluxes providing the maximum transition of tungsten in melted steel-that is, with the greatest possible use of tungsten from a scheelite concentrate $\left(\mathrm{CaWO}_{4}\right)$. A working hypothesis situation was used that the most active reducers of tungsten provide its greatest transition to melted steel, with elements having the greatest affinity to oxygen in activity with a certain macrostructure.

The purpose of this work is to define the structure of the furnace charge of the fluxes providing the maximum transition of tungsten in melted steel using electroslag remelting. In addition, this work will research the physical, chemical and operational properties of tungsten alloy steel.

\section{Materials and Methods}

In works [3, 4], the complex use of a scheelite concentrate as a basis of ceramic alloying flux is used because, in addition to alloying components, it contains most of the necessary components such as slag-forming, gas-forming and ionizing.

As tungsten reduces from oxides $\left(\mathrm{CaWO}_{2}\right)$, it is necessary to use elements that have a greater affinity to oxygen than tungsten. In [7], a number of activities of metals to oxygen in the process of decreasing deoxidizing ability are presented:

$$
\mathrm{Al} \rightarrow \mathrm{Zr} \rightarrow \mathrm{B} \rightarrow \mathrm{Ti} \rightarrow \mathrm{Si} \rightarrow \mathrm{V} \rightarrow \mathrm{Mn} \rightarrow \mathrm{Cr} \rightarrow \mathrm{Mo} \rightarrow \mathrm{W} \rightarrow \mathrm{Fe} \rightarrow \mathrm{Co} \rightarrow \mathrm{Ni} \rightarrow \mathrm{Cu}
$$

It is known from [7] that the elements with an affinity to oxygen are more to the left of iron and to some extent are oxidized; therefore, the extent of the restoration of an alloying element from the oxides of subjects is lower. Then more to the left, there is an element from iron. Conversely, to the left of tungsten, there is an element that has a better recovery ability. For tungsten restoration from a scheelite concentrate, elements can be used that are more to the left of it. An experience of the application of carbon for the restoration of elements in metallurgical production is known.

The most as reduces of tungsten active were accepted in relation to $\mathrm{Al}$ oxygen and graphite. In addition, as reducers of tungsten and oxides are widely applied in production welding surfacing materials ferroalloys (ferromanganese FeMn and ferrosilicium FeSi). It was supposed that under the influence of high temperatures, ferroalloys would decay on elements and $\mathrm{Si}, \mathrm{Mn}$ would restore $\mathrm{W}$ from oxides in a slag bathtub, according to the activity of the metals.

The furnace charge of flux was formed on the basis of a scheelite concentrate with the introduction of $20 \mathrm{wt} \%$ of $\mathrm{CaF}_{2}$ (fluorite) and 4-16 wt $\%$ of the reducer, which increased the contents at the expense of basis reduction. The components of the furnace charge of the flux (scheelite concentrate $\left(\mathrm{CaWO}_{4}\right)$, fluorite $\left(\mathrm{CaF}_{2}\right)$, ferrosilicium $(\mathrm{FeSi})$ and ferromanganese (FeMn)) were crushed to $0.35-0.65 \mathrm{~mm}$. Aluminum was used in the form of powder and shavings with a size of $0.1-0.35 \mathrm{~mm}$, and graphite was used in the form of powder with a size of $0.4-0.56 \mathrm{~mm}$.

Fluxes were made with standard technology. As an additive material, the low-carbon welding wire with a diameter of $3 \mathrm{~mm}$ was accepted.

Further experiments were carried out as follows:

-research and choice of the most rational reducer as a part of the flux for ensuring the maximum transition of an alloying element in a melted additive material;

-research of structure and properties of the received alloys. 
To conduct the research, both standard and original equipment were used. The electroslag surfacing and remelting were carried out on an installation that was designed and made by authors on modes: $\mathrm{I}=350 \ldots 1000 \mathrm{~A}, \mathrm{U}=20 \ldots 90 \mathrm{~B}$. Samples for the analysis were formed in a water-cooled copper crystallizer with a working volume of 40x200 $\mathrm{mm}^{3}$.

The metalgraphic analysis of alloys was carried out using microscopes of Labomet-2 and modular EU of METAM RV-21 at increases to 1000X. Microhardness was defined on the PMT-3M device. The differential and thermal analysis was carried out on the derivatograf Q-1000. The phase structure of the received materials was studied on the Xray DRON-7 diffractometer. The research of the element structure of the received alloys was conducted on an X-ray fluorescence scanning spectrometer "MAKS-GV" and a raster electron probe microscope of ISM-35C JEOL with a prefix of the electron probe microanalyzer - an X-ray spectrometer 35-SDS with wave dispersion.

To determine the physic-mechanical and operational properties of alloys, the following devices were used: for hardness measurement-TSh-2M, TK-14, TP-2; for wear-resistance research - the MI-402 car in the conditions of friction without greasing at a load of $50 \mathrm{~kg} / \mathrm{s}$ and a counter body from the steel 40XH tempered in oil to HRC $60 \ldots 62$.

\section{Results and Discussion}

As shown in fig. 1, the greatest transition of $\mathrm{W}$ to steel is observed being used as the reducer of aluminum shaving and ferrosilicium, and the least active reducer in these conditions is ferromanganese. The presented experimental dependences show that it is not dependent on the reducer type. The greatest transition of tungsten to melted steel is observed at the maintenance of a reducer in the flux furnace charge within $8-12 \mathrm{wt} \%$. From the received dependences, a further increase in the maintenance of a reducer does not lead to an increase in the transition of tungsten in built-up metal. In certain cases, it even reduces it.

The electroslag process used in the furnace charge of the flux of $\mathrm{Al}$ in the form of shaving and grains graphite proceeds steadily: slag is distributed on all surfaces of the builtup metal evenly, and a well forms on the surface of an ingot to protect the melted metal from air access.

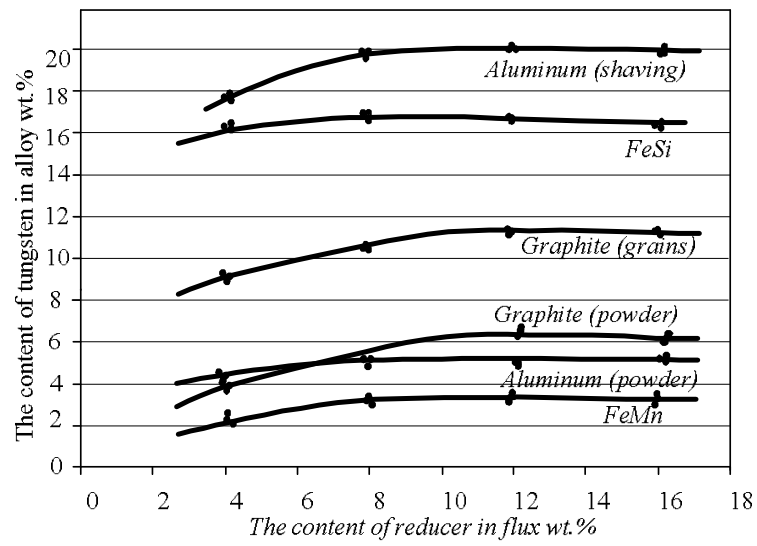

Fig. 1. Dependence of the content of tungsten in an alloy from a quantity of a reducer in the flux furnace charge

As a result of the spectral analysis of the alloys received with using developed fluxes, it was established that all studied reducers allow tungsten to be received from a scheelite concentrate with various degrees of efficiency. 
Application as a reducer of ferromanganese allowed $2.87 \%$ of tungsten to be received in an alloy that slightly exceeds the results received using flux not contained in the structure of traditional reducers and 6.5 times less than when using flux with ferrosilicium. In our opinion, it is caused by the activity with oxygen manganese, which settles close to tungsten, and it has no sufficient recovery abilities.

The conducted research provided an opportunity to establish that the most effective reducers of tungsten from a scheelite concentrate are aluminum, ferrosilicium and graphite.

A particular interest is represented by aluminum and graphite, which are the most active reducers. However, at their use in the developed flux in the form of powder (C), the powder (Al) transition of tungsten to melted steel appeared to be less than when using ferrosilicium. In this regard, the assumption was made that such a phenomenon was caused by technology factors - reducers were entered into skilled fluxes in the form of very small powders of a small weight. As a result, in the course of remelting, they emerged on the surface of a slag bathtub without being dissolved and partially being oxidized by air.

To check this hypothesis, experimental fluxes in which the preservation of structure the size of fraction of reducers were created. For this purpose, aluminum shavings with a grain size of $0.2-0.4 \mathrm{~mm}$ and graphite fractions with a size of $0.4-0.5 \mathrm{~mm}, \mathrm{FeMn}, \mathrm{FeSi}$ with a grain size of $0.35-0.6 \mathrm{~mm}$ were used. Table 1 provides the results of the research of a chemical composition and physic-mechanical properties of alloys of the various fluxes obtained with use. As a result of the research of the chemical composition of the received ingots, it was established that at the expense of an increase in the size of the fractions of aluminum, the amount of the restored tungsten increased by 3.5 times and graphite increase by two times, making 20.6 and $11.4 \mathrm{wt} \%$ respectively.

The slag that remained after remelting contained: when using aluminum, $1.53 \%$ of tungsten, and with a graphite application, 8.38\%, which confirmed a solvency of the hypothesis. The greatest amount of tungsten in alloy No. 3.1 was received with flux use as a reducer in which aluminum shaving was applied. According to the spectral analysis, the average content of tungsten in an alloy was $20.6 \mathrm{wt} \%$. Hardness makes $280-300 \mathrm{HB}$, wear resistance of rather tool steel HS6-5-2-0.5 is 2.73 (Table 1).

Table 1. Physical, mechanical and operational properties of alloys

\begin{tabular}{|c|c|c|c|c|c|c|}
\hline \multirow[b]{2}{*}{$\begin{array}{c}\text { № } \\
\text { fusion }\end{array}$} & \multirow[b]{2}{*}{ Reducer } & \multirow{2}{*}{$\begin{array}{c}\text { Content of } \\
\text { tungsten in alloy } \\
w t \%\end{array}$} & \multirow[b]{2}{*}{$\begin{array}{c}\text { Hardness, } \\
\text { HB }\end{array}$} & \multicolumn{3}{|c|}{ Resistance of steels } \\
\hline & & & & $\begin{array}{c}\text { W1-11- } \\
1 / 2\end{array}$ & $\begin{array}{c}H S 6-5- \\
2-0.5\end{array}$ & $\begin{array}{r}\text { HS12-1- } \\
1.5-0.5\end{array}$ \\
\hline 1 & FeMn & $2.5-2.87$ & $158-174$ & 0.192 & 0.12 & 0.0187 \\
\hline 2 & FeSi & $17.8-18.6$ & $370-390$ & 2.48 & 1.73 & 0.812 \\
\hline 3 & $\mathrm{Al}$ (powder) & $5.5-5.6$ & $156-172$ & 1.43 & 0.647 & 0.431 \\
\hline 3.1 & $\mathrm{Al}$ (shaving) & $19.5-20.6$ & $270-290$ & 2.73 & 1.87 & 0.871 \\
\hline 4 & $\mathrm{C}$ (powder) & $5.4-5.57$ & $160-170$ & 2.12 & 1.08 & 0.442 \\
\hline 4.1 & $\mathrm{C}$ (grains) & $10.6-11.4$ & $256-270$ & 3.62 & 2.08 & 0.842 \\
\hline
\end{tabular}

The alloy No. 3.1 microstructure (fig. 2.) consists of alloyed by ferrite tungsten with microhardness $\mathrm{H}_{\mu}=141-197 \mathrm{HV}$ and pearlite with $\mathrm{H}_{\mu}=198-208 \mathrm{HV}$. In addition, according to the X-ray phase analysis (fig. 3.), intermetallics $\mathrm{Fe}_{2} \mathrm{~W}$ are also present. Scanning in the reflected electrons (fig. 4) showed the phase heterogeneity of an alloy. 
Research of a chemical composition by means of the electron probe microanalysis showed that the matrix of an alloy has a variable structure.

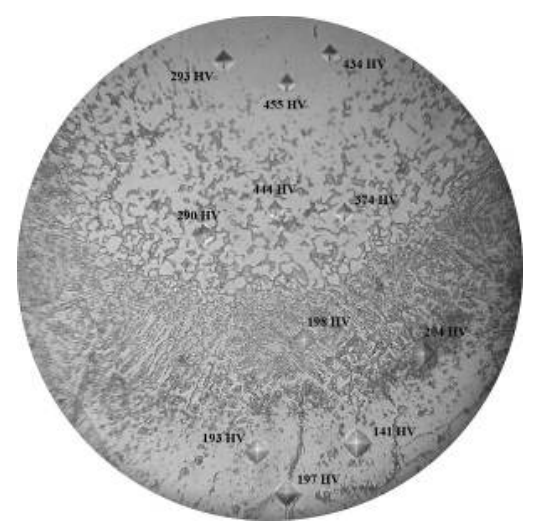

Fig. 2. Alloy No. 3.1 microstructure

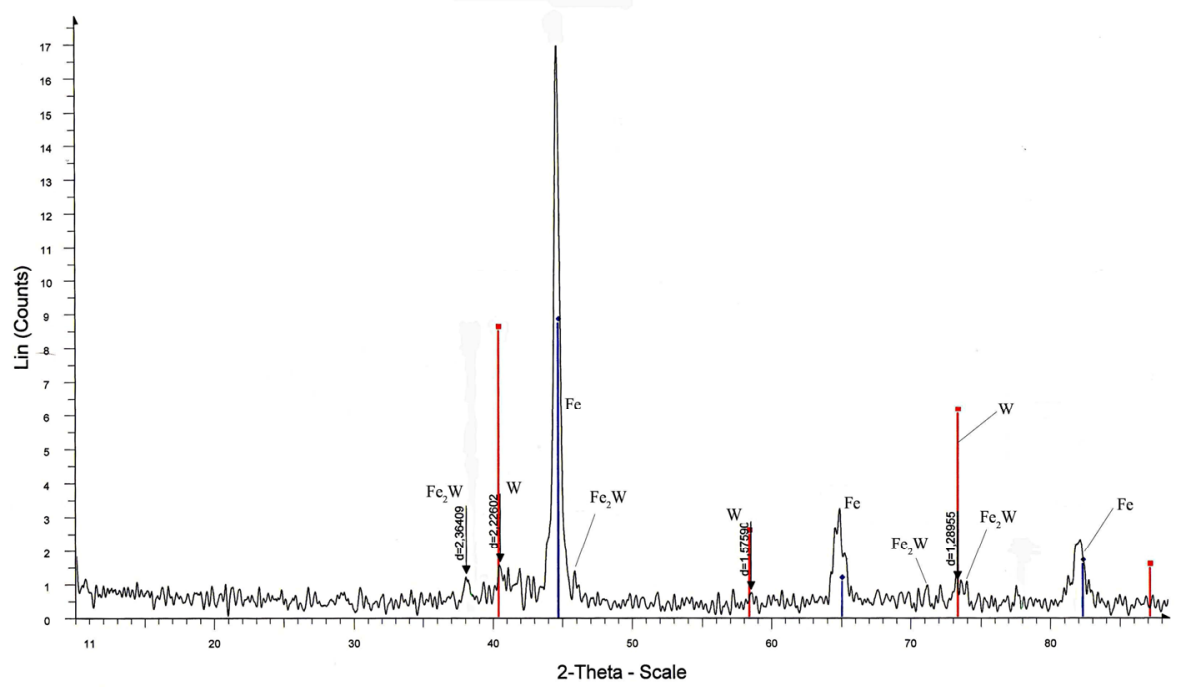

Fig. 3. X-ray diffraction spectrum of alloy No. 3.1.

Point 1 contains $34 \mathrm{wt} \%$ of tungsten and $65 \mathrm{wt} \%$ iron. In points 2 and 3, tungsten (71$89 \mathrm{wt} \%)$ and iron prevail (12-20 wt\%), which confirms the data of the X-ray phase analysis on the existence of intermetallics $\mathrm{Fe}_{2} \mathrm{~W}$ in an alloy and limited firm solution $\mathrm{W}(\mathrm{Fe})$. The microhardness of these phases makes $\mathrm{H}_{\mu}=293-455 \mathrm{HV}$ (fig. 3).

As shown in fig. 4, grain 4 represents a mechanical mix of light and dark phases. The light phase contains about $70 \mathrm{wt} \%$ of tungsten and $30 \mathrm{wt} \%$ of iron, which is similar to phases 2 and 3. The dark phase represents a limited firm solution of tungsten in iron.

Thus, according to conducted research, it follows that tungsten in alloy No. 3.1 was distributed unevenly. Partially, the alloy ferrite and cement carbide formed a chemical compound of $\mathrm{Fe}_{2} \mathrm{~W}$ with iron. Ferrosilicium (alloy No. 2) appeared no less effective a reducer of tungsten from a scheelite concentrate.

As shown, in the X-ray phase analysis (fig. 5) the main phases in an alloy were the ferrite alloyed by tungsten and intermetallics $\mathrm{Fe}_{2} \mathrm{~W}$. 


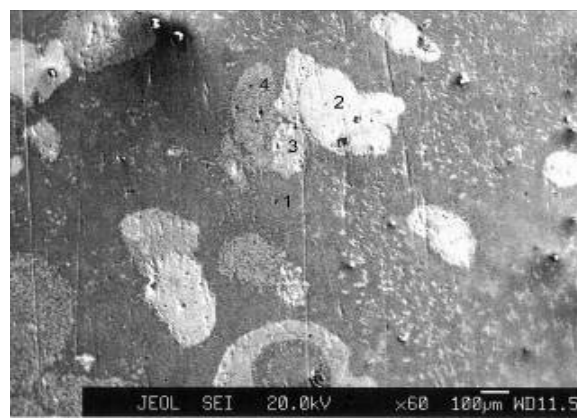

Fig. 4. The image in the reflected electrons of alloy No. 3.1

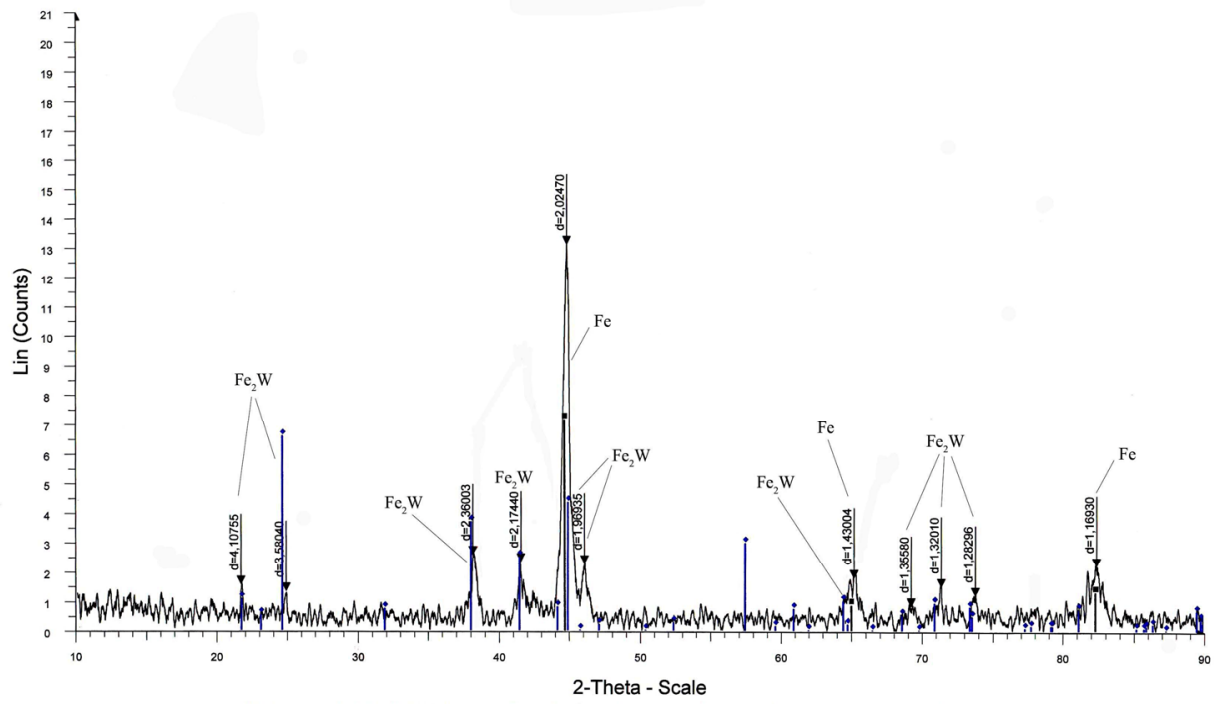

Fig. 5. X-ray diffraction spectrum of alloy No. 2

From the research of a microstructure of alloy No. 2 (fig. 6 ), it was established that in the matrix from the alloyed ferrite with $\mathrm{H}_{\mu}=146-194 \mathrm{HV}$ inclusions intermetallics by $\mathrm{Fe}_{2} \mathrm{~W}$ (up to $0.5 \mathrm{~mm}$ in size) with $\mathrm{H}_{\mu}=294-630 \mathrm{HV}$, which is shown scanning in the reflected electrons, contain about $59 \mathrm{wt} \%$ tungsten and $41 \mathrm{wt} \%$ iron, which are unevenly distributed. In addition, they are surrounded by the area of the alloyed pearlite, with $\mathrm{H}_{\mu}=183-284 \mathrm{HV}$ - the alloyed ferrite divided by a grid with small inclusions intermetallics. It should be noted that the content of tungsten in alloy No. 2 on $8 \mathrm{wt} \%$ is lower than in No. 3.1 (Table 2) at a similar phase structure; however, its hardness for $25 \%$ exceeds the hardness of alloy No. 3.1. In our opinion, the difference in

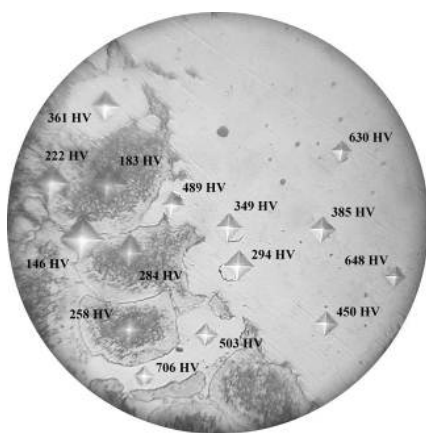

Fig. 6. Alloy No. 3.1 microstructure hardness is caused by the various contents of silicon alloys. In alloy No. 2, the content of silicon made $1.35 \mathrm{wt} \%$, which led to an additional alloying of a low-carbonaceous additive material and an increase in hardness. 
Thus, there is the complex alloying of an alloy tungsten (to $20 \mathrm{wt} \%$ ) and silicon. At the same time, the amount of silicon in alloy No. 2 is 4.5 times higher in relation to alloy No. 3.1 , which in turn causes hardness to increase.

Thus, as the main reducer of tungsten from a scheelite concentrate in ceramic fluxes for electroslag remelting, aluminum use in the form of shaving, FeSi and graphite in the form of grains is recommended.

As a result of the conducted research, we recommend receiving the tungsten in complex alloyed steels close to a chemical composition and to fast-cutting tool steels, electroslag remelting with using fiuxes on the basis of scheelite concentrate.

\section{Conclusions}

1. The possibility of a complex alloying of low-carbonaceous steel through the slag system is available for the variation of various reducers and their macrostructures. The best results are shown using ferrosilicium and carbon.

2. For the first time, the electroslag remelting of low-carbonaceous steel received alloys with the content of tungsten up to $20 \mathrm{wt} \%$.

3. A number of ceramic fluxes on the basis of the scheelite concentrate were developed and approved, allowing electroslag remelting low-carbonaceous to begin to receive high tungsten.

4. Metallographic and dyurometrichesky analyses and the research of operational properties established a complex alloying by tungsten steel with increased hardness and wear resistance.

\section{References}

1. E. Hornbogen. Werkstoffe. (2006).

2. E. Hornbogen, G. Eggeler, E. Werner. Werkstoffe. (2012).

3. E. G. Babenko, A. D. Verkhoturov, V. G. Grigorenko. Basic aspects transport materials technology. (2004).

4. A. D. Verkhoturov Journal of Advanced Materials. 1. (2003).

5. M. Rühle, H. Dosch, E. Mittemeijer European White Book on Fundamental Research in Materials Science. (2001).

6. V. I. Sergiyenko, Rhee Hosen, Centuries Gostishchev, Yu. I. Mulin, E. Kh. Ri, D. Kh. Ri, S. N. Himukhin Problems and prospects of effective use of mineral raw materials of the Far East for production of metal materials. (2009).

7. A. A. Yerokhin Metallurgiya welding. (1978).

8. D. Dakuort Electroslag melting (1973). 